\title{
Quinine - a time for re-evaluation?
}

Quinine was the drug of choice for severe malaria until 2005 and was used extensively in South Africa for this purpose. ${ }^{[1,2]}$ As discussed in this issue of the SAJCC by Mathiba et al. ${ }^{[3]}$ from Chris Hani Baragwanath Hospital (CHBH), two large randomised controlled trials (SEAQUAMAT (South East Asian Quinine Artesunate Malaria Trial) and AQUAMAT (African Quinine v. Artesunate Malaria Trial)) conducted in adults and children, respectively found that mortality was significantly lower with intravenous artesunate and as such it became the recommended agent for severe malaria. ${ }^{[4,5]}$

Artemisinin derivatives clear parasitaemia faster than quinine; they are active against a greater range of the blood-stage parasites than quinine; and they are active against gametocytes. Artesunate, which is water soluble, is the most rapid-acting of the artemisinin derivatives. ${ }^{[5-8]}$

Interestingly, in the studies described above that primarily evaluated mortality, there was also no difference in either with regard to secondary outcomes including neurological sequelae, or requirement for dialysis, mechanical ventilation or inotropes. ${ }^{[4,5]}$ However, as expected, hypoglycaemia was more common in the quinine groups in both studies. It is therefore uncertain what caused the increased mortality in those assigned to receive quinine. If the requirement for organ support was similar, did those patients who died do so without initial organ dysfunction, or did those who developed organ dysfunction have higher sepsis-related organ failure assessment (SOFA) scores and thus do worse? The latter seems unlikely as the need for organ support was similar in survivors and non-survivors.

The other issue of importance is that because the patients in these studies were not necessarily in an intensive care unit (ICU) (SEAQUAMAT does not state where they were managed but, in AQUAMAT, patients were managed in the ward) ${ }^{[4,5]}$ the results cannot be translated to a setting where modern ICU facilities are available. Whereas artesunate certainly seems to reduce mortality in resourcelimited circumstances, ${ }^{[4,5]}$ would the same findings apply if therapy were to be administered in a modern, well-equipped ICU? In other words, did the reduction in mortality relate specifically to the more rapid reduction in parasite count or would more effective management of the organ dysfunction have nullified the mortality differences between artesunate and quinine?

The study in the present issue $\mathrm{e}^{[3]}$ looks retrospectively at patients treated with quinine or artesunate in the ICU; it found no difference between the two drugs. The study was, however, not really powered to detect differences as numbers were relatively small and Acute Physiology and Chronic Health Evaluation (APACHE) scores were relatively low, with a low projected mortality. As such, the study appears at most to demonstrate equivalence of the drugs. This is nonetheless an important observation, and critically important in a setting where supplies of artesunate are unreliable and expensive.

In our ICU (Charlotte Maxeke Johannesburg Academic Hospital), mortality is primarily determined by the severity of illness, i.e. APACHE II score. No patient with an APACHE $<17$ has died and no patient with an APACHE $>28$ has survived (unpublished data). Perhaps this is not surprising as the Glasgow Coma Scale and other measures of organ dysfunction, which are prime determinants of outcome, are critical components of the score. This again makes me wonder why there were no obvious differences in secondary outcomes in the SEAQUAMAT and AQUAMAT studies ${ }^{[4,5]}$ as described above.
Therapy for malaria is multimodal and becomes more complex as severity increases. Essentially, in terms of the Sepsis 3 definitions, malaria can cause sepsis (infection with organ dysfunction) or septic shock (requirement for inotropes/pressors to maintain a mean arterial pressure $>65$ and a lactate $\geq 2$ despite volume resuscitation). ${ }^{[9]}$ Treatment is therefore similar to that of any cause of sepsis, although the chemotherapy obviously differs. Because therapeutic interventions have evolved with time, these changes may also have an impact on mortality that is unrelated to whether quinine or artesunate is used. As an example, and of particular relevance, is the demonstration after SEAQUAMAT and AQUAMAT that bolus administration of fluid may not be of benefit. In the FEAST (fluid expansion as supportive therapy) study in children with sepsis (56\% of whom had malaria), mortality at 48 hours was significantly lower in those who did not receive a fluid bolus ( $7.3 \% \mathrm{v} .10 .5 \%$ in the albumin bolus group and $10.6 \%$ in the saline bolus group). ${ }^{[10,11]}$ These findings may, of course, also have been influenced by the availability or otherwise of dialysis or mechanical ventilation. Bolus administration in the ward may increase the potential for fluid overload which increases mortality, and MAY also increase fluid leak, with increased potential for acute respiratory distress syndrome (ARDS) and requirement for mechanical ventilation..$^{[12-15]}$

A final issue is that as resistance to artesunate increases, we may, if no new drugs appear, be forced to resort back to quinine, which has retained its efficacy over decades. ${ }^{[16]}$

In summary, the study by Mathiba et al. ${ }^{[3]}$ indicates that quinine is at least as effective as artesunate in the ICU setting and that the primary cause of mortality is probably related not to the chemotherapy but rather to the extent of organ dysfunction and the availability of facilities that can provide organ support. This is also important, given the reports of increasing artesunate resistance, particularly in South-East Asia. ${ }^{[17,18]}$ This argument of course presupposes that quinine remains available and that it is dosed correctly, with an initial bolus and a reduction in dose after three days in renal failure, and and that doxycycline be added in severe cases. Perhaps re-education regarding side-effects such as hypoglycaemia, haemolysis, thrombocytopenia and QT prolongation should be considered in those centres where it has not been used for some time.

G A Richards, MB BCh, PhD, FCP (SA), FRCP

Department of Critical Care, University of the Witwatersrand, Johannesburg, South Africa; and Department of Critical Care, Charlotte Maxeke Johannesburg Academic Hospital, Johannesburg, South Africa guy.richards@wits.ac.za

S Afr J Crit Care 2019;35(1):4-6. https:doi.org/10.7196/SAJCC.2019.v35i1.367

1. World Health Organization. Severe falciparum malaria. Trans R Soc Trop Med Hyg 2000; 94(Suppl. 1):S1-S90. https://doi.org/10.1016/S0035-9203(00)90300-6

2. Kothari VM, Karnad DR, Bichile LS. Tropical infections in the ICU. J Assoc Physicians India 2006;54:291-298.

3. Mathiba RM, Nethathe GD, Mathivha LR. Artesunate compared with quinine for the treatment of study. S Afr J Crit Care 2019;35(1):14-19. https:doi.org/10.7196/SAJCC.2019.v35i1.345.

4. Dondorp AN, Nosten F, Stepniewska K, Day N, White N. Artesunate versus quinine for treatment of severe falciparum malaria: A randomised trial. Lancet 2005;366(9487):717-725. https://doi. of severe falciparum malaria: A rand
org/10.1016/s0140-6736(05)67176-0

5. Dondorp AM, Fanello CI, Hendriksen IC, et al. Artesunate versus quinine in the treatment of severe falciparum malaria in African children (AQUAMAT): An open-label, randomised trial. Lancet 2010;376(9760):1647-1657 https://doi.org/10.1016/s0140-6736(05)67176-0

6. Sinclair D, Donegan S, Isba R, Lalloo DG. Artesunate versus quinine for treating severe malaria. Cochrane Database Syst Rev 2012;(6):CD005967. https://doi.org/10.1002/14651858.cd005967.pub4 
7. Rosenthal PJ. Artesunate for the treatment of severe falciparum malaria. N Engl J Med 2008;358(17):1829. https://doi.org/10.1056/nejmct0709050

8. Ter Kuile F, White NJ, Holloway P, et al. Plasmodium falciparum: In vitro studies of the pharmacodynamic properties of drugs used for the treatment of severe malaria. Exp Parasitol 1993;76(1):85. https://doi.org/10.1006/expr.1993.1010

9. Singer M, Deutschman CS, Seymour CW, et al. The Third International Consensus Definition for Sepsis and Septic Shock (Sepsis-3). JAMA 2016;315(8):801-810. https://doi.org/10.1001/ jama.2016.0287

10. Maitland K, Kiguli S, Opoka RO, et al. Mortality after fluid bolus in African children with severe infection. N Engl J Med 2011;364(26):2483-2495. https://doi.org/10.1056/nejmoal101549

11. Maitland K, George E, Evans J, et al. Exploring mechanisms of excess mortality with early fluid resurction: Insights from the FEAST trial BMC Med 2013:11:68 https//doi org/10.3410 /f.717990733.793473222

12. Krishnan A, Karnad DR. Severe falciparum malaria: An important cause of multiple organ failure in Indian intensive care unit patients. Crit Care Med 2003;31(9):2278-2284. https://doi. org/10.1097/01.ccm.0000079603.82822.69
13. Bruneel F, Tubach F, Corne P, et al. Severe imported falciparum malaria: A cohort study in 400 critically ill adults. PLoS One 2010;5(10):e13236. https://doi.org/10.1371/journal.pone.0013236

14. Cheng MP, Yansouni CP. Management of severe malaria in the intensive care unit. Crit Care Clin 2013;29(4):865-885. https://doi.org/10.1016/j.ccc.2013.06.008

15. Taylor WR, Hanson J, Turner GD, White NJ, Dondorp AM. Respiratory manifestations of malaria. Chest 2012;142(2):492-505. https://ddoi.org/10.1378/chest.11-2655

16. Thanh NV, Thuy-Nhien N, Tuyen NT, et al. Rapid decline in the susceptibility of Plasmodium falciparum to dihydroartemisinin-piperaquine in the south of Vietnam. Malar J 2017;16:e27. https://doi.org/10.1186/s12936-017-1680-8

17. Phyo AP, Thu AM, Swe LL, et al. Poor response to artesunate treatment in two patients with severe malaria on the Thai-Myanmar border. Malaria J 2018;17(1):30. https://doi.org/10.1186/ s12936-018-2182-z

18. Imwong M, Hien TT, Thuy-Nhien NT, Dondorp AM, White NJ. Spread of a single multidrug resistant malaria parasite lineage (PfPailin) to Vietnam. Lancet Infect Dis 2017;17(10):1022-1023. https://doi.org/10.1016/s1473-3099(17)30524-8 